\title{
Dance + Engineering: A Collaboration for Freshmen Engineering Design Students
}

\author{
AnnMarie Thomas ${ }^{1}$, Amy Miller ${ }^{2}$, Heather Spicuzza ${ }^{2}$ \\ University of St. Thomas, Saint Paul, $\mathrm{MN}^{1} /$ The Ordway Center for the Performing Arts, \\ St. Paul, $\mathbf{M N}^{2}$
}

\begin{abstract}
This paper examines a collaboration between the freshmen-level engineering graphics and design class at the University of St. Thomas (UST), dance students at Macalester College and the University of St. Thomas, Ordway Center for the Performing Arts, and Diavolo Dance Theater. Traditionally, students in ENGR171 completed a design project for a fictitious client. Through this collaboration, however, the students were given a real client, a more open-ended initial design brief, and a strict timeline. The engineering students participated in a movement workshop to familiarize themselves with some of the methods the dancers would be using. Additionally, they met with their clients to establish user needs and engineering specifications for the project. Students' designs were then commented on, via the internet, by dancers, set designers, potential users of the set piece, and potential manufacturers of the set piece. The students' deliverables included written descriptions of their designs, CAD models, and oral presentations. This paper will address some of the strengths and weaknesses of this collaborative project, as well as lessons learned that can be applied to future collaborative projects.
\end{abstract}

\section{INTRODUCTION}

Engineering Graphics and Design (ENGR171) is a four-credit required course in the Mechanical Engineering major. It is typically taken during fall or spring semester of the freshman year and is usually the first or second course the student takes in the engineering department. The other engineering course that electrical and mechanical engineering students take during the freshman year is a one-credit Introduction to Engineering course. The following is the ENGR171 course description as written in University of St. Thomas' course catalog:

"Through a combination of lectures, hands-on computer lab time, and design projects, students will learn to read, and create, engineering drawings and use computer-aided-design (CAD) terminology and technology. Topics covered will include the engineering design process, rapid prototyping, principles of projection, and introductory methods of representation and constructive geometry."

Historically, this course has focused on drafting and CAD, (Hennessey 2002, 2005), though in the past two years, St. Thomas faculty has added an emphasis on design process, product design, and rapid prototyping. In addition to a final project in which students take apart a complex object and create, using the SolidWorks CAD program, a full packet of engineering drawings and models for the object, students must complete two design projects during the semester. In a typical semester, these projects are: 
- Project 1: “Chair Design” Students must design a chair for a specified imaginary client that can be built using a single piece of standard plywood. After creating a CAD model of this chair, students are taught how to use a laser cutter to make scale models of the chair.

- Project 2: "Chess Project" Students must design a chess set for their choice of one of three possible imaginary clients (a blind individual, a child, or a beginner chess player.) They must create a list of user needs for the chess set, and then create a CAD model of a full set of chess pieces that meet these needs. Students are then given the opportunity to have one of their designed pieces 3D printed in the design lab.

The goal of these projects is to encourage students to apply a structured design process to an open-ended design challenge.

In the spring of 2009, the lead instructor for ENGR171 was approached by representatives from Ordway Center for the Performing Arts as part of their Campus Connections program. The Campus Connections program (funded by The Wallace Foundation) is a campus-wide partnership with Ordway Center designed to build bridges between the Ordway and communities of students, faculty, staff, and alumni. The program's goal is to develop effective ideas and practices to integrate arts-based methodologies into teaching practice, as well as to build current and future audiences and enhance participation in the arts. As part of this program, the Ordway was interested in exploring cross-curricular connections to the presentations within their World Music and Dance Series. Introducing the engineering students to dance through work with Los Angeles-based Diavolo Dance Theater, seemed logical because of the company's reliance on objects as central to its aesthetic, and, further, would allow for students focused in two very different disciplines (science-based and arts-based) to form a practical working relationship based on mutual creativity.

Engineering is a natural fit with a Diavolo project as their dance style is very physical and always involves the use of an object or set piece. In their artistic statement, the importance of set pieces is stressed: "Architectural structures or sculpted adaptations of everyday items - sofas, doors, stairs - provide the backdrop for dramatic and risky movement, revealing metaphors for the challenge of maintaining human relationships in modern environments" (Heim). During a collaborative planning process with team leaders from UST's Engineering Department, Macalester's Dance Department, and Ordway's Community Engagement department, a process emerged in which UST Engineering students, Macalester and UST student lead dancers, and dancers from both schools would be actively and collaboratively engaged to work with Diavolo in the creation and presentation of an original dance piece, to be performed during the Spring 2010 Macalester Dance Concert. All students would work with the Diavolo team to learn the company's specific aesthetic and would apply skills from their own disciplines to the final project. A set piece would be created and Diavolo company members would guide the Macalester and UST dancers through the process of choreographing a dance around the constructed set piece. Thus, for the Spring 2010 semester, Project 1 (the chair project described above) would be replaced with an involved project in which the students would design a set piece to be the central physical element in a dance performed during the Macalester Spring 2010 Dance Concert. 
It was decided that students from ENGR171 would individually design and model (using SolidWorks), a set piece based on design requirements and feedback given to them by members of Diavolo and the student lead dancers from Macalester and UST. Members of Diavolo, the student lead dancers, and representatives of the Ordway would discuss the proposed designs and then select one to be constructed. A build team from the University of St. Thomas would then create the physical set piece based on the selected design. This set piece would then be delivered to the Ordway for the intensive rehearsals between Diavolo members and Macalester/UST dancers, during which a dance involving the set piece would be choreographed. Below, this process will be discussed in detail.

\section{PROJECT LAUNCH}

One challenge presented by this project was the timeline. Typically, the first design project for ENGR171 would be presented approximately at the end of the fifth week of the semester. However, in order to have a set piece delivered to the Ordway in time for the intensive rehearsals with Diavolo and the Macalester/UST dancers, the first project was launched at the beginning of the fourth week of the semester. On the Monday of the fourth week of the semester, Jacques Heim, Artistic Director of Diavolo, along with Garrett Wolf, veteran Diavolo company member, joined the ENGR171 students for the project launch.

During the initial launch, the Diavolo representatives showed video footage of their performances and discussed the aesthetic of Diavolo. Students were then given the following project description:

For this project we are partnering with Ordway Center for the Performing Arts, dancers from Macalester College and the University of St. Thomas, and Diavolo Dance Theater of Los Angeles. A group of dancers will be training with Diavolo company members in order to create and perform a piece in the style of Diavolo. That's where you come in! Diavolo dances use props and/or set pieces. Using your knowledge of the design process and SolidWorks, you are going to design a piece for the Macalester/UST dancers. To do this, we will be working with dancers from both Macalester/UST and Diavolo. One of you will have your design chosen to be built into a set piece in which a dance will be choreographed around. Your set piece must be able to be built out of one to three pieces of plywood, 8' $x 4$ ' $x$ 1/16". Your design must not require the use of any fasteners, with the exception of fasteners made out of the plywood itself. (Note that if your design is chosen for construction, we will work with you to design supports for it which may include the use of additional wood and/or fasteners.) We will then be building 1/12 scale models using thin plywood and the UST Design Lab's laser cutter. As you work on this project, please reflect on the lectures, readings, discussions of the engineering design process that we had at the beginning of the semester!

The requirements for the project's deliverables were also presented to the students at this time. There were two sets of deliverables for this project, as described below. Students were given a chance to ask questions of the Diavolo representatives. 
The next class session consisted of a movement workshop for the engineering students led by Jacques Heim and Garrett Wolf of Diavolo. Creative thinking was emphasized throughout the workshop and students were encouraged to use trust in order to accomplish the movement exercises, which included leaping into fellow classmates' arms during the Diavolo "Superman" exercise. The engineering students were also given a short assignment to choreograph a series of movements on a folding chair, which helped them gain insight into the dancers' role of moving and choreographing on a set piece.

\section{PROJECT DELIVERABLES}

The following are the instructions that the students received for the first deliverable set. Please note: Blackboard is an online forum used by UST for class discussions and postings.

Part A: Preliminary designs [due 10 days after the project launch] Please post the following on Blackboard by noon. Note that there is a scanner available for your use in OSS 105 [engineering student lounge].

- A half-to-full page write-up explaining your design, and why you think it is appropriate for the Macalester and UST dancers, based on your discussions and work with Diavolo.

- 1-2 pages of sketches (hand drawn) showing your design in enough detail to give the viewer an idea of the finished piece. You will be receiving feedback on these drawings from the dancers and choreographers.

The students were encouraged to be bold in their ideas, and to focus on hand sketches and written descriptions which would give the viewer a sense of what the design would look like when completed, with enough information and detail such that constructive criticism could be given. During the first few weeks of ENGR171, students are given instruction in various handsketching methods. The sketching part of this project is meant to encourage students to continue practicing their drawing skills. Students were able to get feedback from dancers and choreographers of Diavolo, staff members from Ordway Center for the Performing Arts, the lab and lecture instructors from ENGR171, the student lead dancers, and the shop manager from the University of St. Thomas, who would lead the build team for the set piece, using an on-line discussion board format. Samples of two of the hand-drawn sketches, minus the accompanying write-up, can be found in Figure 1.
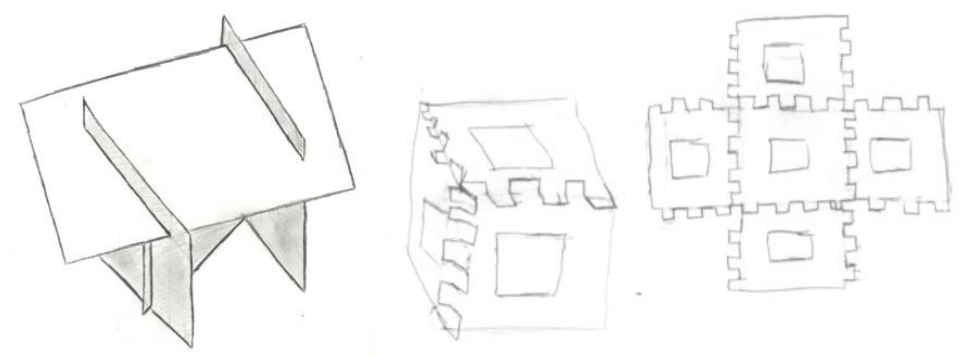

Figure 1: Samples of the initial sketch phase of the design project. (Work by Aisha Adam and Dimitri Angelo) 
Following this on-line exchange of ideas, along with accompanying discussion in the ENGR171 lecture and lab, students proceeded to Part B of the project.

Part B: Presentation, models and drawings of your final design [due 18 days after the project launch, 8 days after the completion of Part A] Create a new folder, entitled "Project 2," in your ENGR171 directory. In this directory, include:

- SolidWorks models of each part for your final design. (Parts should be fully dimensioned for the actual size of the piece.)

- An assembly file for the completed piece

- (A) SolidWorks drawing file(s), saved in a .dwg format, to use as a cutting file

○ 8" by 4" page for each sheet of plywood that you are using

- No border or title block

- Front views only of each piece, laid out however you intend for them to be cut from the wood at 1:12 scale

○ Note that this is not an engineering drawing, but rather the cutting template for the laser cutter. We will be using this file to produce your wooden model.

- Please submit a packet containing the following:

- One page describing your final design. What was the idea behind it? How did your design change based on feedback? What do you think some of the challenges would be if we decided to build this full scale for the Macalester dancers?

- Printouts of the SolidWorks model (assembly) of your piece

- A printout of the SolidWorks drawing(s) described above

○ An 8.5x11 inch poster designed using PowerPoint which shows:

- An assembly drawing of your design

- A short description of your design

- A title for your design

- Your name and class information (ENGR171 Spring 2010)

- Any images or sketches which you think help explain your design

In class you will have 60 seconds to give a short presentation on your design, with the poster projected on the screen as a visual aid. The lead student dancers and Ordway staff, in addition to your classmates, will be there. The final design will be chosen after these presentations.

Samples of student posters can be found in Figure 2. A sample of a student's SolidWorks assembly and corresponding laser cutter file can be found in Figure 3.

\section{DESIGN SELECTION}

Eighteen days after the project launch, the students gave their 60-second (single PowerPoint slide) presentations showing their designs. Samples of these slides can be found in Figure 2. In the audience for these presentations were the ENGR171 faculty and students, the student lead dancers, and representatives from Ordway Center for the Performing Arts. Representatives from Diavolo were not present due to their travel schedule. During the presentation, individuals 
involved in choosing the final design to be constructed for the Macalester dance took notes on which designs seemed most promising. After the mini-presentations (which took one full class period), the ENGR171 instructor met with the student dance leads and the Community Events Coordinator from the Ordway to choose the final design. Based on the results of this meeting, a short list of approximately five of the most promising designs were emailed to Jacques Heim, Artistic Director of Diavolo, who then joined the group by phone. In the course of the discussion with Jacques Heim, the final design was chosen. As will be discussed below, the group chose the final design based on a variety of factors, including how well the design would work for a group of 20 dancers.

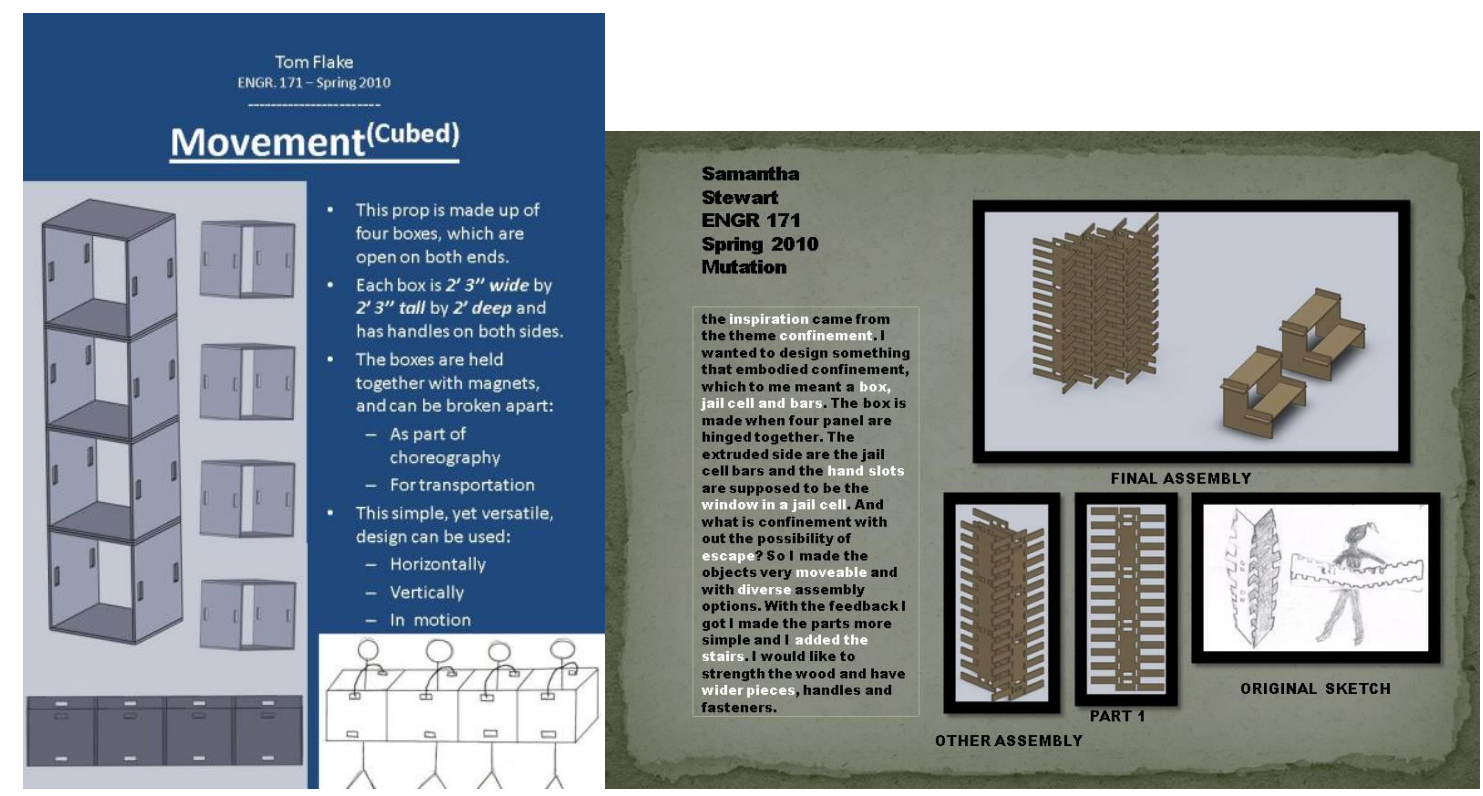

Figure 2: Samples of student slides for the 60 second project pitch presentations. The slide on the left represents the design that was ultimately chosen for construction.

(Work by Tom Flake and Samantha Stewart)
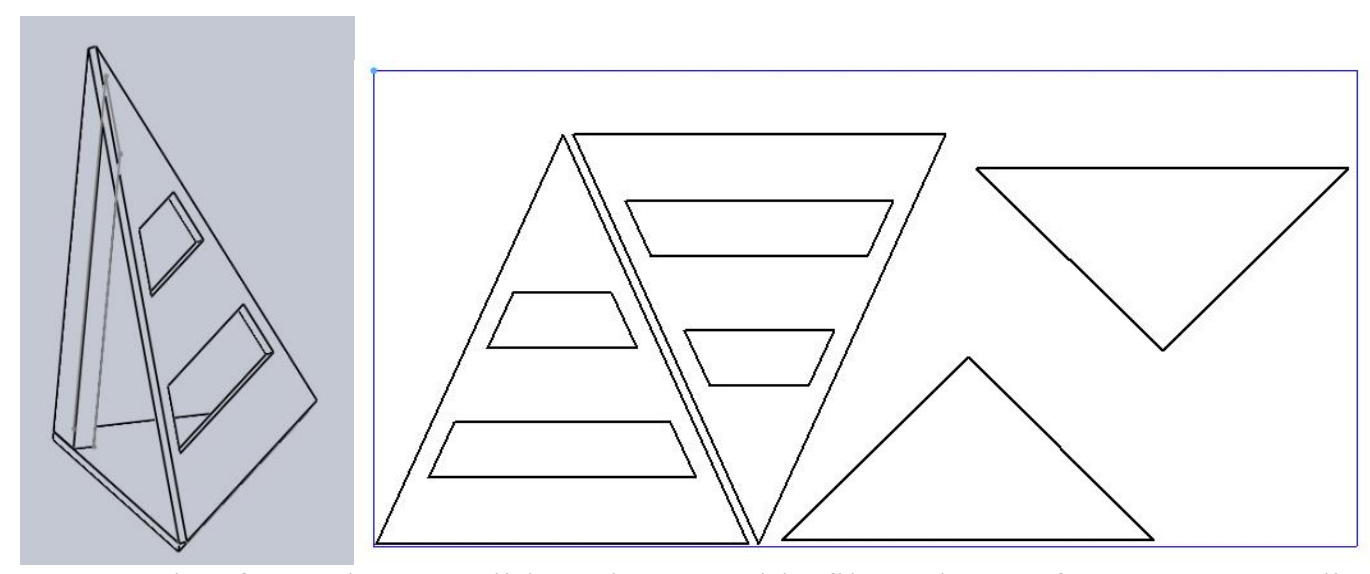

Figure 3: A sample of a student's SolidWorks assembly file and one of two corresponding laser cutting templates that are associated with this assembly. (Work by Matthew Hanson) 


\section{PROJECT BUILD}

Three students who had previously taken ENGR 171were hired to work with the School of Engineering lab manager to build props based on the design provided by the student. It is important to note that the design which was built was true to the concept designed by the student, but not the physical design. One challenge of this project was that ENGR171 has no prerequisites, and thus the students did not necessarily have any experience with physics or manufacturing. The build team worked with the ENGR171 instructor as well as the student designer to revise the design to one that would be sturdy and buildable (Figure 4).

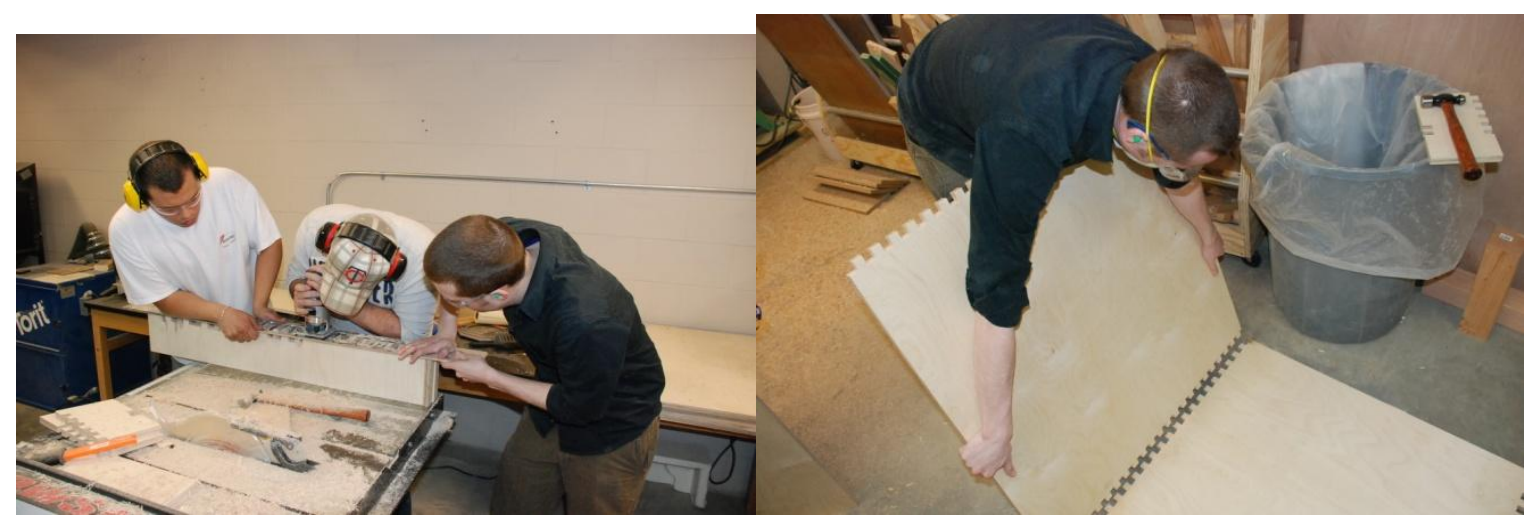

Figure 4: Undergraduate engineering students constructing the final set piece for the Macalester and UST dancers. (Photographs courtesy of John Angeli)

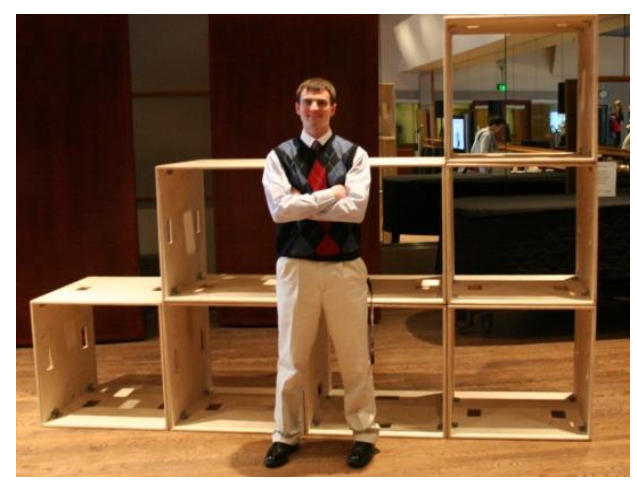

Figure 5: Student Tom Flake with the set piece created using his design.

While only one design was built at full scale (see Figure 5), every student who submitted a laser cutting file (as described in the instructions for Part B of the project and pictured in Figure 3 ) had their parts cut on a laser cutter. Some of these scale models can be seen in Figure 6 . The final build involved creating two sets of the chosen design (thus using double the material limit that was specified in the instructions). This was done at the request of the Diavolo members. 


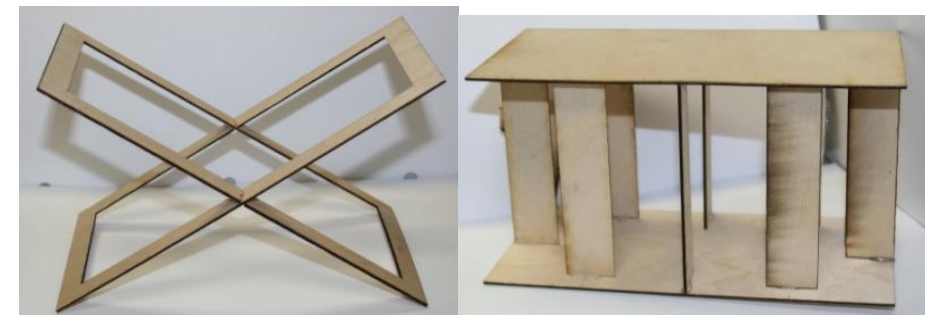

Figure 6: Scale (1/12) models of the students' models constructed using the laser cutter. (Designs by Anthony Suchla, and Stephen Bang)

\section{SOCIAL COMPONENT}

Students had the unique opportunity to attend a performance by Diavolo at Ordway Center for the Performing Arts a few weeks after the final design presentations. Prior to the show the ENGR171 students socialized with the Macalester and UST dancers, Diavolo members, and staff of the Ordway. The chance to socialize with others involved in the project strengthened the sense of community related to this project. Watching Diavolo perform with large set-pieces on stage also gave the engineering students the chance to see commissioned design works in use, giving a "real-life" factor to the project.

\section{STUDENT FEEDBACK}

As part of the Ordway's Campus Connections program, a facilitator from the Ordway ran a tuning session with the students the day after the optional visit to the Diavolo performance (approximately two weeks after the "winning" design was chosen). Each student was given a chance to verbally share their warm feedback about the project as well as their cool feedback, in the form of "I wonder..." statements. Both sets of feedback were helpful in pointing out what worked well, what could have been done differently, and further ideas for the project if done again.

In the warm feedback section of the tuning, the following were some of the aspects that the students thought were most successful about this project:

- Having the actual client (the student lead dancers, the Diavolo Artistic Director and a Diavolo company member) at the project launch meeting was very helpful.

- The online critiques of the preliminary designs were found to be helpful. At least one student discussed how this feedback led him to change his design between the initial sketch stage and the final model stage.

- The chance to build a relationship with the client was a positive experience - having the opportunity to work with an actual client who would use the design (not just a hypothetical assignment).

- The movement workshop with Diavolo was helpful. The engineering students noted that this helped them think about movement possibilities, and also that such an experience was fun since it was something that an engineering student wouldn't normally get the chance to do ("able to experience instead of just watching").

- Many students mentioned that having the chance to design something "real" as freshmen was very exciting for them. As one student said, "What was designed was actually going to be built - made it real - the design has a "life."' 
- Competition between designers was seen by the students to be a positive aspect in that it encouraged them to produce creative, original designs.

- Learning about dance as well as working with Diavolo and learning their aesthetic style helped the students design.

- Students appreciated the chance to meet many different people from different fields.

- The project taught students about collaboration and incorporating many crucial points of view, which is important for arts-integration work

Anecdotally, students seemed much more engaged with this project than they typically have been when completing the chair project (described above) in previous semesters. Based on the warm feedback, it seems that the key factors in the students' involvement are likely the participation of a real client who was available to give students feedback, and the knowledge that their work may be turned into a physical object used by the client.

During the cool feedback portion, students were all invited to talk about things that may have been done differently. Below is a sampling of this feedback. In italics below each suggestion, we have included a response to explain the rationale behind our choice:

- I wonder if next time, there could be no material constraint - instead, have a budget to allow for more creativity?

For this project, we constrained the materials so that the build team could begin construction of the set as soon as a design was chosen and complete it in a timely manner (the build team had only one week to build the set before intensive rehearsals for the dancers began). Additionally, as this project was done early in the semester, the engineering students had limited knowledge of SolidWorks. By constraining the project to plywood, we ensured that students would be able to create a design using simple sketching and extrude tools in SolidWorks.

- I wonder if the project could happen at a different point during the semester? Some students felt ill-prepared for doing a design project this early in the semester, given the limits of their SolidWorks experience. Given the deadline for delivering the set piece, we could not push this project back any further in the semester.

- I wonder if we could have more time together to talk about design, an important part of the collaboration, and to talk about the final product? Again, due to the need for the dancers to have the finished set piece by the middle of the semester, we were constrained to a tight timeline.

- I wonder what would happen if we worked in teams rather than individually, allowing us to exchange ideas and possibly develop more creative designs?

This is a good point and one that we struggle with whenever we design ENGR171 projects. Since this is one of the first college classes the students take, we like them to do a mix of individual and group projects to strengthen their technical skills, as well as their teamwork abilities. The final ENGR171 project is always done in teams.

\section{CONCLUSION}

From an instructor's standpoint there were a few unique challenges and benefits that came from this project. First and foremost, when collaborating with the many partners involved in this 
project, the ENGR171 instructor lost a level of control over the class project. Flexibility was key.

Because the students were freshmen, many of whom had no college-level physics classes, the students did not have the skills to do static and dynamic analysis of their designs. In some ways this project could be considered a concept design project as opposed to an engineering design project. Were this class populated with students who were further along in their engineering studies, force analysis could be added to the project. Additionally, the students' knowledge of manufacturing methods was extremely limited, so the project organizers understood that the project build crew and ENGR171 instructor would have to redesign the chosen set piece to make it buildable. For the chosen design, this was indeed the case and the edges of the box, critical for attaching the sides together, were redesigned. Figure 7 shows the boxes in their final form, being used by the student dancers.

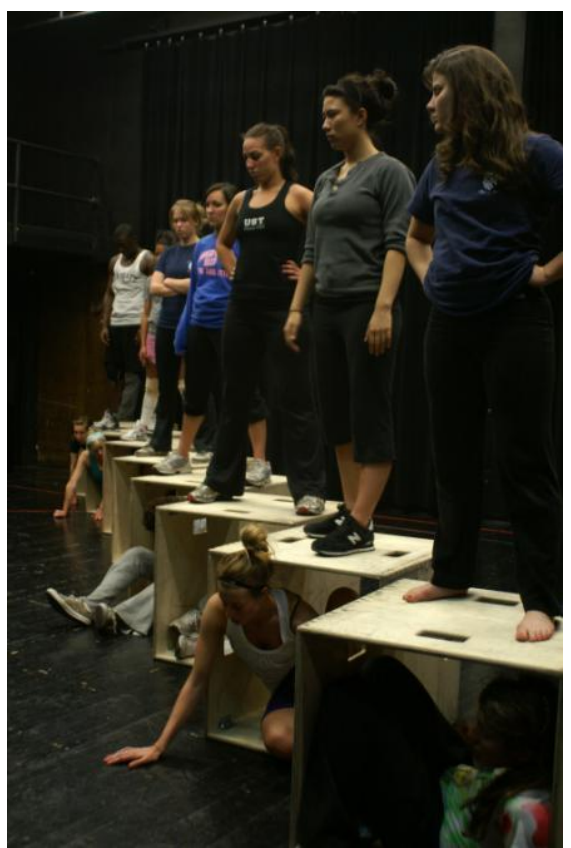

Figure 7: Student dancers choreographing on the chosen set piece. (Photo courtesy of Amy Miller.)

The opportunity to have first year students working with real clients added a level of excitement to this course that is absent in cases where the projects involve fictitious clients. Their attention to the project's requirements and user needs was stronger, likely owing to the fact that they were presenting their projects to the client and getting real feedback. While this particular project is unlikely to be repeated due to the unique nature of the opportunity, we will attempt to find other clients that ENGR171 students can work with in order to duplicate the success of this project.

\section{ACKNOWLEDGEMENTS}

We are grateful to the Ordway Center for the Performing Arts' Campus Connections program for offering us this opportunity. We would like to thank John Angeli, William Johnson, William Besser, and Tom McCulloch for constructing the final set pieces. The project could not have happened without Jacques Heim, Garrett Wolf, Renee Larsen and the entire Diavolo company, 
Allen Moon of David Lieberman Artists' Representatives, Shelley Quiala, Wynn Fricke, Becky Heist, Susanna Hostetter, Amanda Leaveck, Sarah White, and the dancers of Macalester and University of St. Thomas. This project was funded in part by The Wallace Foundation Excellence Award grant to the Ordway.

\section{REFERENCES}

Heim, J., Artistic Vision. Retrieved on June 28, 2010 from http://www.diavolo.org.

Hennessey, M. P., Rhode, P. S., and Jaedike, A. C., “A Gallery of CAD Generated Imagery: Pedagogical

Reflections," ASEE Annual Conference and Exposition, Portland, OR, June 12-15, 2005.

Hennessey, M. P., Jaedike, A. C., and Rhode, P. S., "Galleries of CAD Generated Imagery," ASEE 2002: North Midwest Regional Conference, University of Wisconsin, Madison, WI, October 10-12, 2002.

\section{BIOGRAPHICAL INFORMATION}

ANNMARIE POLSENBERG THOMAS is an assistant professor of Engineering at the University of St. Thomas. Her teaching and research focus on Design and K-12 Engineering Education. Prior to her appointment at UST, she was a faculty member at Art Center College of Design.

AMY MILLER is the Community Events Coordinator at Ordway Center for the Performing Arts. She coordinates events and residencies surrounding the Target World Music and Dance Series ${ }^{\circledR}$ and the Campus Connections Program.

HEATHER SPICUZZA is the Programming Director of World Music, Dance and International Children's Festival at Ordway Center for the Performing Arts. She oversees programming of world-class artists presented in the Target World Music and Dance Series ${ }^{\circledR}$, Performing Arts Classrooms, and the International Children's Festival. 